\title{
Effects of maternal traits and individual behavior on the foraging strategies and provisioning rates of an income breeder, the Antarctic fur seal
}

\author{
Birgitte I. McDonald ${ }^{1, *}$, Michael E. Goebel ${ }^{2}$, Daniel E. Crocker ${ }^{3}$, Yann Tremblay ${ }^{1}$, \\ Daniel P. Costa ${ }^{1}$ \\ ${ }^{1}$ Department of Ecology and Evolutionary Biology, Long Marine Laboratory, 100 Shaffer Road, University of California, \\ Santa Cruz, California 95060, USA \\ ${ }^{2}$ Antarctic Ecosystem Research Division, National Oceanic and Atmospheric Administration, 8604 La Jolla Shores Drive, \\ La Jolla, California 92038, USA \\ ${ }^{3}$ Department of Biology, Sonoma State University, 1801 East Cotati Avenue, Rohnert Park, California 94928, USA
}

\begin{abstract}
The ability of an animal to acquire energy will affect its allocation to offspring and will ultimately influence fitness. This study investigated the relative influence of maternal traits, seasonal demands of pup-rearing, and individual effects on the foraging behavior of 27 female Antarctic fur seals Arctocephalus gazella at Cape Shirreff, Livingston Island, Antarctica during 2 austral summers (2005 and 2006), using time depth recorders. The relationship between foraging and allocation was investigated using pup growth as an indicator of parental investment. While female diving behavior differed between years, trip duration was below the $10 \mathrm{yr}$ mean and did not differ between the 2 years of the study, indicating favorable feeding conditions in both years. Study year and maternal age accounted for a significant amount of the variation in day and night dive characteristics, while maternal mass influenced only parameters related to night dive effort. As the season progressed, females increased their dive effort at night, made shorter daytime dives, with more bout diving. Individual variability accounted for a significant amount of the variation in all foraging parameters. Females could be assigned to one of 4 behavioral dive groups (high effort, low effort, intermediate effort with high dive rate, and intermediate effort), based on 13 dive parameters although year instrumented and age appeared to be important in determining group affiliation. Age, mass, year, and trip number influenced diving behavior; however, there was no relationship between foraging behavior and pup growth rate, except in young females.
\end{abstract}

KEY WORDS: Diving behavior · Energy allocation · Individual effects · Pinniped · Antarctic fur seal

\section{INTRODUCTION}

Foraging behavior plays an important role in the ability of individuals to allocate energy to their offspring and ultimately influences fitness (Stearns 1992). Optimal foraging theory predicts that animals should adjust their foraging behavior to optimize energy acquisition and use in order to maximize fitness (MacArthur \& Pianka 1966, Stephens \& Krebs 1986). The optimal strategy will be affected by intrinsic con- straints such as age, mass, and physiological capability and extrinsic factors associated with the abundance and distribution of prey (Stephens \& Krebs 1986, Daunt et al. 2007). However, we still have a poor understanding of the relative importance of these factors in most animals and how the factors may interact to affect foraging behavior and ultimately allocation to offspring.

In otariids (sea lions and fur seals), foraging behavior and offspring provisioning are linked because females alternate between periods at sea foraging and time 
ashore nursing their pup. Otariids are required to return regularly to the breeding site to feed their young and are, thus, defined as central place foragers (Orians \& Pearson 1979). As such, otariids are restricted in the distance they can travel and time they can spend foraging by the physiological demands of the pup. Mothers should optimize their foraging behavior in order to maximize the rate of food delivery to their young.

Individual traits such as age, mass, and condition often influence foraging behavior. Foraging efficiency (energy gained per unit effort) increases with age and experience in many species (Galbraith et al. 1999, Daunt et al. 2007, Skorka \& Wojcik 2008), potentially because an individual's ability to find and handle prey improves with experience (Orians 1981, Galbraith et al. 1999). In central place foragers, experience may influence the point at which the individual decides to return to their offspring. Body mass may also play an important role in foraging behavior. In diving vertebrates, mass can affect breath hold capacity and thus diving behavior (Schreer \& Kovacs 1997). Larger size is also beneficial because it allows for more energy obtained during the foraging trip to be stored (Georges \& Guinet 2000), and it may act as a buffer after a poor foraging trip. The effects of size and experience on foraging behavior may be more apparent when resources are scarce or difficult to access (Georges \& Guinet 2000, Lea et al. 2006).

A variety of studies have documented changes in foraging behavior in response to temporal changes in the distribution and/or abundance of prey (Boyd et al. 1994, Kato et al. 2003, Beauplet et al. 2004). Many of these studies have been conducted in years of contrasting prey abundance and have found that, in years of limited prey availability, foraging success is often low. When prey is less abundant some species alter their foraging behavior (Draulans 1982, McKnight 1998), e.g. by increasing the amount of time spent foraging (Hill \& Ellis 1984, Percival \& Evans 1997, Crocker et al. 2006, Costa 2007). Low foraging success and efficiency often result in reproductive failure (Jonsson et al. 2002, Bolger et al. 2005, Jodice et al. 2006). More subtle changes in foraging behavior may occur even if prey is abundant because of a change in distribution and size of prey (Petit et al. 1990, Miller \& Trivelpiece 2008). Variation in foraging behavior between different populations shows the behavioral plasticity in many species that allows them to adapt to local environments (Tremblay \& Cherel 2003, Lea et al. 2008). In addition to understanding how intrinsic and extrinsic factors influence foraging behavior, it is also important to link the variation in foraging behavior to allocation of energy to offspring.
In the present study we examine proximate factors affecting the foraging behavior of female Antarctic fur seals (Arctocephalus gazella) of known age, and the relationship between foraging and pup growth - an index of female investment. Lactating females exhibit regular provisioning patterns alternating 2 to $5 \mathrm{~d}$ at sea feeding with 1-2 d on shore during the 4 mo lactation period (Doidge et al. 1986). Because prey is located at depth and fur seals typically transit near the surface, diving is thought to accurately reflect foraging (Boyd \& Croxall 1992). Previous research investigating foraging behavior suggests that Antarctic fur seals vary their behavior in response to fluctuations in prey resources (Boyd et al. 1994, Lea et al. 2006, Costa 2007). Additionally, they demonstrate significant variation in their foraging behavior both across their range and at a single location (McCafferty et al. 1998b, Lea et al. 2002, Robinson et al. 2002).

We investigated the relative influence of maternal traits and individual quality on foraging behavior and pup growth rate. We tested the following predictions: (1) Maternal traits influence foraging behavior. We anticipated that young females would have longer trips and spend more time foraging due to lack of experience (Goebel 1988, Gentry 1997). We also predicted that younger, smaller animals would dive to shallower depths and would focus their diving at night when food is found at shallower depths. Breeding female fur seals range in mass from 25 to $60 \mathrm{~kg}$, with younger animals usually being smaller, potentially leading to significant variation in diving ability. (2) Females demonstrate distinct foraging strategies. In other populations of Antarctic fur seals, female identity explains much of the variation in diving behavior (McCafferty et al. 1998b) and in one population, females exhibited 4 distinct strategies (Lea et al. 2002). (3) Foraging behavior and maternal traits influence pup growth rate. Pups of larger females making short, regular foraging trips have faster growth rates, particularly in years of poor foraging conditions (Guinet et al. 2000, Lea et al. 2006).

\section{MATERIALS AND METHODS}

Study colony and seals. This study was conducted at Cape Shirreff, Livingston Island, Antarctica. Livingston Island, part of the South Shetland Island chain, is located near the tip of the Antarctic Peninsula. Cape Shirreff $\left(62^{\circ} 28^{\prime} \mathrm{S}, 60^{\circ} 46^{\prime} \mathrm{W}\right)$ projects north into the Drake Passage. This site is home to the highest latitude breeding colonies of Antarctic fur seals. The primary study area consisted of 4 colonies spanning $1 \mathrm{~km}$ on the east side of Cape Shirreff. The population increased for almost 3 decades since re-colonization in 
the 1960s but appears to have stabilized during the last decade, with pup production varying between 1700 and 2500 pups per year over the last 10 yr (Goebel et al. 2007). Studies were conducted during the austral summers of 2005/06 and 2006/07 (referred to as 2005 and 2006, respectively).

We used a pool of known-age female fur seals established by tagging 500 pups annually since the 1997/98 season as part of the US Antarctic Marine Living Resources (AMLR) program. Additionally, all adult females captured since 1999/2000 have been tagged and aged by extracting a post-canine tooth and counting the cementum rings (Goebel et al. 2001). Numbered plastic tags (Dalton Jumbo Rototags, Dalton ID Systems) were attached to the trailing edge of each foreflipper of both mothers and pups.

Seal capture and device attachment. Thirty-three lactating females and their pups were caught approximately 1 d postpartum (2005, $\mathrm{n}=17$; 2006, $\mathrm{n}=16$ ). Median date of capture was December 10 in 2005 and December 17 in 2006. Of the adult females, 29 were tagged in previous years either as pups or adults and were of known age. Subjects were selected from 2 age categories: young ( 4 to $6 \mathrm{yr}$ olds) or prime-aged (8 to $14 \mathrm{yr}$ olds). Ten of the young females were primiparous, or first-time breeders. Four females had never been caught before and had a post-canine tooth removed at recapture to determine age. Three of these females were older than $14 \mathrm{yr}$, but because their behavior was not different from that of prime-aged females, they were included in the prime-age class. Females were captured with hoop nets, sedated with an intravenous injection of midazolam (5 mg) and anesthetized with isoflurane gas (from 0.5 to $5 \%$ ) with oxygen via a portable field vaporizer, administered through a cone shaped mask (Gales \& Mattlin 1998). Once the females were sedated, a time depth recorder (TDR; one of 2 models: MK9, Wildlife Computers, $85 \times$ $15 \times 15 \mathrm{~mm}, \mathrm{~N}=30$; Sensus Ultra, ReefNet, $45 \times 33 \times$ $25 \mathrm{~mm}, \mathrm{~N}=3$ ) and a radio transmitter (ATS, $50 \times 25 \times$ $15 \mathrm{~mm}$ ) were attached to the fur dorsal to the midline, between the scapulae, using 5 minute epoxy (Devcon). Females were weighed using a tension dynamometer $( \pm 0.2 \mathrm{~kg}, \mathrm{MSI})$, and standard length (straight length from tip of tail to tip of nose) was measured to the nearest centimeter. A body condition index was calculated by using the residuals from the regression of body length and mass (Trites 1991). Females were placed in a box until they recovered in order to prevent harassment from males (time in box, $10 \pm 4 \mathrm{~min}$ ). Once awake and mobile, the female was released with her pup back into the territory where she was caught. Females were recaptured after completing at least 6 foraging trips, using the same procedure. Different individuals were sampled in the 2005 and 2006 studies.
Pups of instrumented females were weighed, marked, sexed, and tagged during the initial capture of the female. The pup was recaptured and weighed 24 to $48 \mathrm{~h}$ after the female departed on her first foraging trip, to obtain a post-perinatal mass. Waiting 24 to $48 \mathrm{~h}$ after female departure ensured that the pup had digested the milk and provided a more accurate mass (Guinet et al. 1999). Pups were again captured 24 to $48 \mathrm{~h}$ after their mother departed on her 7 th foraging trip. Mean daily growth rate was calculated for the period between the 2 mass measurements. While we initially tried to control for pup sex (have all pups of one sex), it was not possible to obtain a sufficient sample size of young females; therefore, the number of pups of each sex was matched across age classes.

Data processing. Diving records were obtained from a total of 27 of the 33 instrumented females $(2005, n=13$; $2006, \mathrm{n}=14)$. Only 5 trips were recorded for one female in 2006 (07-4-nn) due to her late arrival and longer trips, but she was included in the analysis; all other females completed 6 trips. As pups age they spend more time in the water (McCafferty et al. 1998a, Baker \& Donohue 2000), and many are lost to leopard seal predation. Females whose pup died before they completed 6 trips were excluded from the analysis $(n=3)$.

Foraging trip duration was determined from TDR data and confirmed with radio transmitter data and visual observations. Diving behavior variables were analyzed in MATLAB (MathWorks) using a custom-written dive analysis program (IKNOS, Y. Tremblay unpubl.) which calculates a zero offset correction at the surface and identifies dives on the basis of a minimum depth and duration. MK9 TDRs had a depth resolution of $0.5 \mathrm{~m}$ and sampled every $2 \mathrm{~s}$. ReefNet TDRs had a depth resolution of $0.01 \mathrm{~m}$ and sampled every $6 \mathrm{~s}$. In order to compare and combine data from the 2 tag types, the MK9 data were sub-sampled to a $6 \mathrm{~s}$ resolution. This also allowed us to compare our results with previous studies that used a $5 \mathrm{~s}$ resolution. The minimum depth for defining a dive was set at $4 \mathrm{~m}$ to eliminate transiting dives and for better comparison with other studies on fur seals. The minimum duration considered to be a dive was $18 \mathrm{~s}$, or 3 times the sampling rate.

Dive bouts were identified using an iterative statistical technique (Boyd et al. 1994, Lea et al. 2002). Minimum criterion for a bout was 3 dives greater than $6 \mathrm{~m}$ deep during a 20 min period, in order to exclude travelling dives but include shallow feeding dives. Once this criterion was met, the mean and 95\% confidence limit (CL) of the surface interval within the bout were calculated. The following dive was included in the bout if the preceding surface interval was less than the $95 \%$ CL. The upper 95\% CL was recalculated after the inclusion of each additional dive. The bout ended once the preceding surface interval exceeded the 95\% CL. 
In order to determine whether the observed bout pattern represented structured behavior rather than a random distribution of dives, we randomized the dives in a dive record and reran the bout analysis. This was repeated 1000 times for each dive record. If the number of bouts per replicate was greater in the randomizations than the true dive record in more than $95 \%$ of the cases, then the dive record was considered to have bout structure (Lea et al. 2002).

Mean values for the foraging parameters for each trip, and an overall 6-trip mean for each parameter, were calculated for each female (called trip mean and female mean, respectively). Previous research indicates that Antarctic fur seals exhibit diel variations in their behavior (Boyd et al. 1991, Lea et al. 2002) so we analyzed several variables separately for daytime and nighttime. Additionally, since foraging primarily takes place at night, several dive effort parameters are calculated only for nighttime (Lea et al. 2002). The following parameters were determined for each trip and female: (1) day mean dive depth (m), (2) night mean dive depth (m), (3) day mean dive duration (s), (4) night mean dive duration (s), (5) day mean bottom time (s), (6) night mean bottom time (s), (7) night dive rate (dive $\mathrm{h}^{-1}$ ), (8) proportion of nighttime diving at sea (sum of duration of night dives $\geq 4 \mathrm{~m}$ depth divided by total nighttime spent at sea [\%]), (9) vertical depth travelled per hour of night (2 times the sum of nightly dive depths divided by number of night hours $\left.\left[\mathrm{m} \mathrm{h}^{-1}\right]\right)$, (10) proportion of total vertical depth dived at night (\%), (11) number of dives at night as a proportion of all dives (\%), (12) proportion of dives in bouts (\%), (13) number of dives per bout, (14) mean trip duration (d), (15) proportion of time at sea (trip duration divided by the sum of foraging trip durations and shore visit durations [\%]). Daytime duaration was calculated on the basis of sunrise and sunset times for Cape Shirreff, Livingston Island, obtained from the US Naval Observatory at http://aa. usno.navy.mil/data. Nighttime duration ranged from 3.8 to $7.5 \mathrm{~h}$ during the study period.

Statistics. We used linear mixed models to investigate the effects of female age, female mass, female condition, year, and trip number on diving behavior response variables. Trip number was used as a temporal index of environmental change and/or to represent behavioral changes to meet changing pup demands. The dimensionality of the diving behavior data was reduced using a Principal Component Analysis (PCA) on the trip means of the diving variables. A quartimax rotation was used to increase the loading of individual variables onto the principal components. Separate mixed models were run with each principal component as a response variable. Individual was included as a random subject effect to account for the lack of independence and to investigate individual effects on div- ing behavior. Models were run using PROC MIXED in SAS (SAS Institute) with a variance components covariance structure. Covariance structures, including autoregression covariance structures, were evaluated using the corrected Akaike's information criterion $\mathrm{AIC}_{\mathrm{C}}$ and the variance components covariance structure was selected because it best fit the model. All predictor variables and 2 relevant interaction terms were included in the model and then eliminated on the basis of Wald-F statistics; only effects that were significant $(p<0.05)$ were retained. Model residuals were examined for approximate normality.

Multidimensional scaling techniques (MDS) and cluster analysis were used to identify groups of females using similar foraging strategies. The female means of 13 foraging parameters (day and night bottom time were excluded due to their strong correlation with dive duration) were included in both a cluster and MDS analysis using the PATN v3 software package (Blatent Fabrications). A Gower metric association matrix was used to create a dissimilarity matrix. The Gower metric has built-in standardization and was therefore chosen to handle this data set with large variation among the variables (Gower 1971). The unweighted pair group arithmetic averaging (UPGMA) clustering algorithm was applied to the dissimilarity matrix (Belbin et al. 1992), and the hierarchical agglomerative fusion strategy was used to group similar animals and produce a dendrogram. Semi-strong hybrid multidimensional scaling (Belbin et al. 1992) was used to visualize the relationships in 3 dimensions (see Lea et al. 2002).

A general linear model (GLM) was used to investigate the relationship between foraging behavior and pup growth rate. To reduce the dimensionality of the diving behaviour a PCA analysis was performed as above, using overall female means. Effects of the diving principal components, pup sex, maternal age class, and maternal mass on growth rate were analyzed.

Data were tested for normality and homogeneity of variances prior to analysis when necessary. Multiple ANOVAs were used to compare dive parameters between the age classes and year instrumented. All means are expressed as mean $\pm \mathrm{SD}$ and results were considered significant at $\mathrm{p}<0.05$. Analysis was conducted in Systat 11 (Systat Software).

\section{RESULTS}

\section{Maternal characteristics and pup growth rate}

Mean age of young females was $5 \pm 1$ yr $(n=12,10$ of which were primiparous), and the mean age of primeaged females was $13 \pm 3 \mathrm{yr}(\mathrm{n}=15)$. Female postpartum mass was $46.9 \pm 7.5 \mathrm{~kg}$ (range: 32.8 to $59.5 \mathrm{~kg}$ ). 
There was no difference in mass or condition between the 2 years of the study ( $p>0.05$, Table 1). Younger females were lighter and shorter than prime-aged females (Table 1).

Mean pup growth rate was $124 \pm 30 \mathrm{~g} \mathrm{~d}^{-1}$. There was no difference in pup growth rate between years or for young and prime-aged females (Table 1). Male pups had a greater growth rate than female pups (male: $140 \pm 26 \mathrm{~g} \mathrm{~d}^{-1}$, female: $111 \pm 28 \mathrm{~g} \mathrm{~d}^{-1}, t=-2.66, \mathrm{df}=24$, $\mathrm{p}=0.014)$. There was no effect of female age, mass, or condition on pup growth rate $(p>0.05)$. Significant differences in diving behavior were observed between the 2 years (Table 2) even though trip duration and pup growth rate indicate that food availability was good for both years (Table 1).

\section{Influence of maternal traits and individual on foraging behavior}

Maternal traits, year, trip number, and individual all influenced foraging behavior (Table 3). Female body condition was the only independent variable that did not influence diving behavior (Table 3). The 15 diving variables in the PCA using means from each trip (161 trips) loaded onto 4 components, which accounted for $77.1 \%$ of the variance. Variables related to dive effort (night dive frequency, percent of nighttime spent submerged, percent of dives at night, rate of vertical distance traveled at night, percent of vertical distance traveled at night, trip duration, and percent of time at sea) loaded most strongly onto principal component one (PC1) and accounted for $25.1 \%$ of the total variance. Nighttime dive characteristics (night mean dive depth, night mean dive duration, and night mean bottom time) loaded most strongly onto principal component 2 (PC2) and accounted for $22.0 \%$ of the total variance. The third principal component (PC3) represented daytime dive characteristics (day mean dive depth, day mean dive duration, and day mean bottom time) and accounted for $18.0 \%$ of the total variance. The final component (PC4) represented bout behavior (percent of dives in a bout and mean dives per bout) and accounted for $12.0 \%$ of the total variance.

Individual, mass, and trip number were significant in explaining the variability in PC1 (dive effort; Table 3). Dive effort decreased with increasing mass and increased as the season progressed. PC2 (nighttime

Table 1. Arctocephalus gazella. Female characteristics, feeding cycles, and pup growth rates by year (austral summer) and age class. Values are mean $\pm \mathrm{SD} ; \mathrm{ns}=$ not significant

\begin{tabular}{|c|c|c|c|c|c|c|c|}
\hline & $\begin{array}{l}\text { Age } \\
(\mathrm{yr})\end{array}$ & $\begin{array}{l}\text { Mass } \\
(\mathrm{kg})\end{array}$ & $\begin{array}{l}\text { Length } \\
\text { (cm) }\end{array}$ & $\begin{array}{l}\text { Body condition } \\
\text { (residuals) }\end{array}$ & $\begin{array}{l}\text { Trip duration } \\
\text { (d) }\end{array}$ & $\begin{array}{c}\text { Time at sea } \\
(\%)\end{array}$ & $\begin{array}{c}\text { Pup growth rate } \\
\qquad\left(\mathrm{g} \mathrm{d}^{-1}\right)\end{array}$ \\
\hline $2005 / 06(n=13)$ & $10 \pm 5$ & $48.7 \pm 8.5$ & $131 \pm 7$ & $-0.59 \pm 4.61$ & $2.93 \pm 0.55$ & $59.7 \pm 5.0$ & $129 \pm 26$ \\
\hline $2006 / 07(\mathrm{n}=14)$ & $9 \pm 4$ & $45.3 \pm 6.3$ & $125 \pm 7$ & $0.55 \pm 3.57$ & $3.14 \pm 1.19$ & $63.1 \pm 8.9$ & $117 \pm 33$ \\
\hline Young $(\mathrm{n}=12)$ & $5 \pm 1$ & $40.6 \pm 4.7$ & $121 \pm 6$ & $-1.28 \pm 4.47$ & $3.29 \pm 1.17$ & $64.1 \pm 6.9$ & $119 \pm 37$ \\
\hline Prime $(n=15)$ & $13 \pm 3$ & $52.1 \pm 4.9$ & $133 \pm 5$ & $1.03 \pm 3.57$ & $2.84 \pm 0.66$ & $59.4 \pm 7.3$ & $126 \pm 25$ \\
\hline \multicolumn{8}{|c|}{$p$-values from ANOVA } \\
\hline Year & ns & ns & 0.037 & ns & ns & ns & ns \\
\hline Age & - & $<0.0001$ & $<0.0001$ & ns & ns & ns & ns \\
\hline Interaction & - & ns & ns & ns & ns & ns & ns \\
\hline
\end{tabular}

Table 2. Arctocephalus gazella. Dive parameters by year (austral summer) and age class. Values are mean $\pm \mathrm{SD} ; \mathrm{ns}=\mathrm{not}$ significant

\begin{tabular}{|c|c|c|c|c|c|c|c|c|c|c|c|}
\hline & \multicolumn{2}{|c|}{ Depth (m) } & \multicolumn{2}{|c|}{ Duration (s) } & \multicolumn{2}{|c|}{ Bottom time (s) } & \multicolumn{2}{|c|}{ Dive rate (dives $\mathrm{h}^{-1}$ ) } & \multicolumn{2}{|c|}{ Time spent diving (\%) } & \multirow{2}{*}{$\begin{array}{c}\% \text { of total } \\
\text { dive } \\
\text { at night }\end{array}$} \\
\hline & Day & Night & Day & Night & Day & Night & Day & Night & Day & Night & \\
\hline $2005 / 06$ & $18.8 \pm 2.5$ & $15.4 \pm 3.0$ & $89 \pm 11$ & $69 \pm 7$ & $32 \pm 6$ & $21 \pm 4$ & $8.0 \pm 0.8$ & $20.1 \pm 3.4$ & $19.9 \pm 3.0$ & $37.4 \pm 4.3$ & $35.2 \pm 5.3$ \\
\hline $2006 / 07$ & $27.7 \pm 4.6$ & $13.9 \pm 3.9$ & $99 \pm 11$ & $58 \pm 8$ & $33 \pm 6$ & $16 \pm 2$ & $7.5 \pm 1.6$ & $23.5 \pm 4.6$ & $20.5 \pm 3.7$ & $37.2 \pm 6.4$ & $42.7 \pm 7.6$ \\
\hline Young & $22.2 \pm 5.1$ & $14.2 \pm 3.6$ & $88 \pm 11$ & $59 \pm 8$ & $29 \pm 5$ & $17 \pm 3$ & $8.3 \pm 1.4$ & $24.1 \pm 4.1$ & $20.3 \pm 4.3$ & $38.8 \pm 5.7$ & $41.5 \pm 8.4$ \\
\hline Prime & $24.4 \pm 6.4$ & $14.9 \pm 3.5$ & $99 \pm 10$ & $66 \pm 9$ & $36 \pm 5$ & $20 \pm 5$ & $7.4 \pm 1.0$ & $20.0 \pm 3.9$ & $20.2 \pm 2.4$ & $36.1 \pm 4.9$ & $37.2 \pm 6.3$ \\
\hline \multicolumn{12}{|c|}{$p$-values from ANOVA } \\
\hline Year & $<0.0001$ & ns & 0.004 & 0.005 & ns & 0.003 & ns & ns & ns & ns & 0.011 \\
\hline Age & 0.021 & ns & 0.002 & 0.042 & 0.004 & ns & 0.002 & 0.02 & ns & ns & ns \\
\hline Interaction & ns & ns & ns & ns & ns & ns & ns & ns & ns & ns & ns \\
\hline
\end{tabular}


Table 3. Arctocephalus gazella. Mixed-effect model results showing the influence of maternal traits, year and trip number on female diving behaviour. Parameters that were not significant were excluded from the final model and are indicated by ns unless the parameter was significant in an interaction term. Individual describes percentage variance accounted for by individual. No $F$-statistic is calculated for Individual

\begin{tabular}{|c|c|c|c|c|c|c|c|c|}
\hline \multirow[t]{2}{*}{$\begin{array}{l}\text { Predictor } \\
\text { variables }\end{array}$} & \multicolumn{2}{|c|}{$\begin{array}{c}\mathrm{PC} 1 \\
\text { (dive effort) }\end{array}$} & \multicolumn{2}{|c|}{$\begin{array}{c}\mathrm{PC} 2 \\
\text { (night dive traits) }\end{array}$} & \multicolumn{2}{|c|}{$\begin{array}{c}\text { PC3 } \\
\text { (day dive traits) }\end{array}$} & \multicolumn{2}{|c|}{$\begin{array}{c}\text { PC4 } \\
\text { (bout behavior) }\end{array}$} \\
\hline & Var. $(\%)$ & $\mathrm{p}$ & Var. (\%) & $\mathrm{p}$ & Var. $(\%)$ & $\mathrm{p}$ & Var. (\%) & $\mathrm{p}$ \\
\hline \multirow[t]{2}{*}{ Individual } & 97.2 & 0.002 & 28.9 & 0.019 & 43.3 & 0.009 & 56.27 & 0.004 \\
\hline & $F$ & $\mathrm{p}$ & $F$ & $\mathrm{p}$ & $F$ & $\mathrm{p}$ & $F$ & $\mathrm{p}$ \\
\hline Age & - & ns & - & ns & 20.19 & $<0.001$ & - & ns \\
\hline Mass & 7.41 & 0.008 & 1.72 & 0.192 & - & ns & - & ns \\
\hline Body condition & - & ns & - & ns & _- & $\mathrm{ns}$ & - & ns \\
\hline Year & - & ns & 4.39 & 0.038 & 23.44 & $<0.001$ & - & $\mathrm{ns}$ \\
\hline Trip number & 8.11 & $<0.001$ & 2.34 & 0.046 & 2.70 & 0.017 & 53.92 & $<0.001$ \\
\hline Mass $\times$ Year & - & ns & - & ns & - & ns & - & ns \\
\hline Mass $\times$ Trip number & - & ns & 2.44 & 0.039 & - & ns & - & ns \\
\hline
\end{tabular}

dive characteristics) was significantly influenced by individual, trip number, year, and the interaction term Mass $\times$ Trip number (Table 3). Night dive duration and depth decreased in the middle of the study period, and during the first trip heavier females were diving deeper and longer at night, hence the significance of the interaction term. In 2005 females dived for longer at night. Individual, age, year, and trip number predicted variation in PC3 (daytime dive characteristics). For PC3, day dive duration and bottom time increased with age. Day dive duration and bottom time decreased with increasing trip number, and females dived deeper and longer in 2006. Individual and trip number significantly influenced variation in PC4 (bout diving behavior; Table 3 ). The percentage of dives in a bout increased while the mean number of dives per bout decreased as the season progressed.

Results from the multiple ANOVA's also highlighted some of the age and year differences. Mean trip durations of young and prime-aged females were not significantly different although there was a greater variation in trip durations in the young females (Table 1). Young females did not dive as deeply as prime-aged females during the day, but there were no differences at night (Table 2). Young females also had significantly shorter dives both during the day and night when compared to prime-aged females (Table 2). This resulted in the young females spending less time in the foraging zone (bottom time) per dive than older females. Younger females had a significantly higher dive rate during both the day and night relative to prime-aged females (Table 2).

There was no difference in trip duration between the 2 years of the study, but there was greater variation in 2006 (Table 1). Although trip duration and proportion of time spent at sea were similar between the 2 years of the study, fur seals dived deeper during the day in 2006.
However, there was no difference between the 2 years when comparing night mean dive depth (Table 2). Day dive duration was also longer in 2006 (Table 2). Although the fur seals were diving to the same depth at night during both years of the study, night dive duration was significantly longer in 2005. Similarly, there were no significant differences in mean trip duration and percent time spent at sea between young and prime-aged females, but there were differences in several dive characteristics between young and prime-aged females.

\section{Diving behavior groups}

Cluster analysis produced a dendrogram of the dissimilarity in diving behavior, indicating 4 behavioral dive groups among the 27 females (Fig. 1). These 4 groups were identified by multidimensional scaling, with the ordination of the data in 3 dimensions yielding 4 groups with an acceptably low stress value of 0.092 (Fig. 2). For simplicity, each group was given a name based on its characteristic dive parameters. A group of primiparous females (Group 1: young high effort, $N=4$ ) was the first to separate out (Fig. 1). They spent a significantly greater proportion of night hours diving, significantly more time at sea, and had significantly longer trip durations (Table 4). The next group to separate out consisted of a single seal that had the lowest effort (Group 2: low effort, $\mathrm{N}=1$ ). In addition to having the lowest nighttime dive rate, least amount of time spent at sea, and shortest trips, she had some of the deepest and longest dives (Table 4). The last 2 groups had similar trip durations, time spent at sea, and time spent diving at night, but Group 3 (intermediate effort, high dive rate) dived to significantly shallower depths at night for shorter durations, resulting in an increased nighttime dive rate compared to Group 4 (intermediate effort; Table 4). Group 3 also dived to sig- 


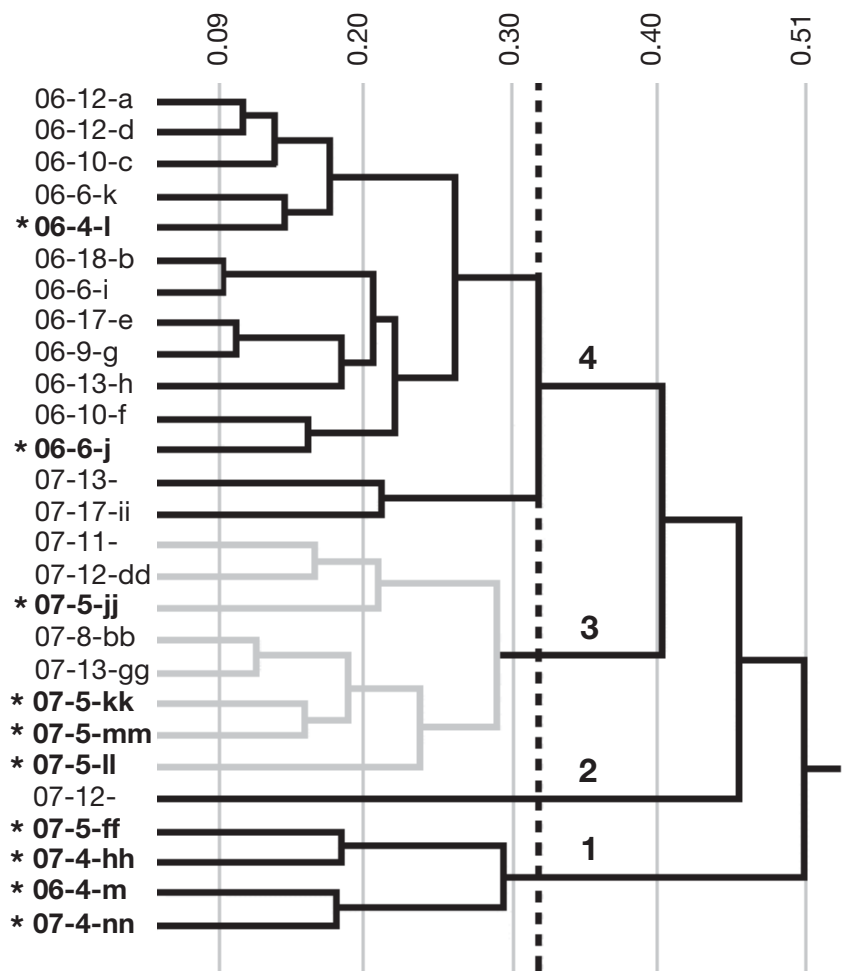

Fig. 1. Arctocephalus gazella. Fusion dendrogram indicating 4 behavioral groups $(1=$ high effort; $2=$ low effort; $3=$ intermediate effort, high dive rate; 4 = intermediate effort) determined from 13 foraging and diving parameters from 27 Antarctic fur seals. Individual female names on the left indicate study year, age of seal, and unique letter ID. Names of primiparous females are in bold and indicated with an asterisk. Values along the top show relative distance between nodes

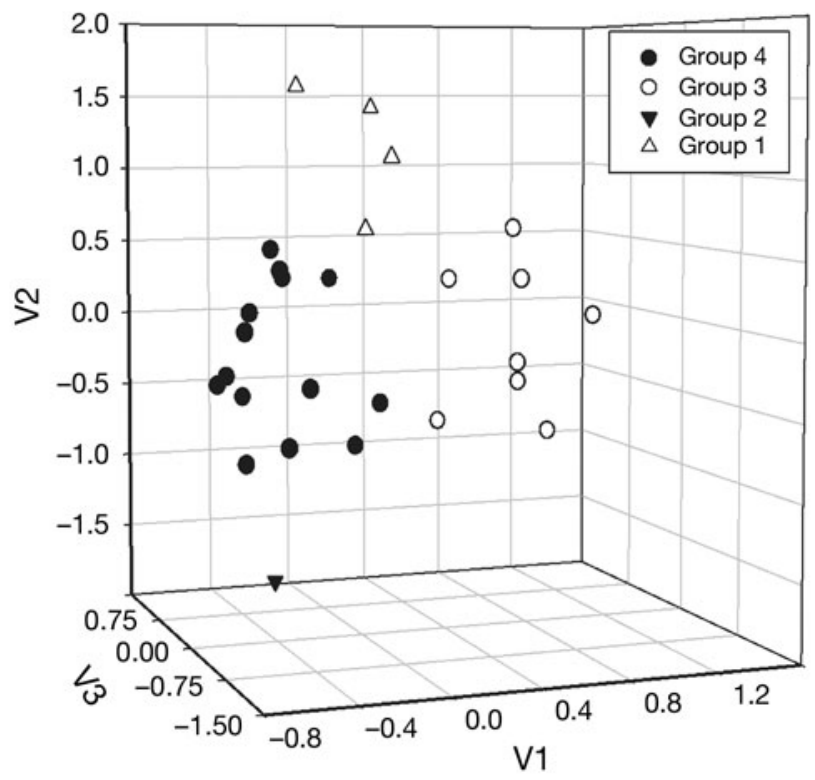

Fig. 2. Arctocephalus gazella. MDS ordination plot showing the 4 behavioral groups $(1=$ high effort; $2=$ low effort; $3=$ intermediate effort, high dive rate; 4 = intermediate effort) nificantly greater depths during the day. All females instrumented in 2005, excluding 1 first-time breeder, clustered into Group 4. Most females instrumented in 2006 clustered into Group 3; however, some 2006 females were found in all 4 clusters. Although 4 primiparous females separated out, other primiparous females clustered in both Groups 3 and 4 (Fig. 1).

\section{Relationship between foraging behavior and pup growth rate}

The 15 dive parameters in the PCA analysis using female means ( $\mathrm{n}=27$ females) loaded onto 3 components and accounted for $77.0 \%$ of the variance. Similar to the previous PCA analysis, variables related to dive effort loaded most strongly onto PC1, nighttime dive characteristics loaded most strongly onto PC2, and daytime dive characteristics loaded most strongly onto PC3 $(30.8,23.8$, and $18.0 \%$ of the total variance, respectively). However, bout characteristics did not load strongly onto any of the components.

The GLM with the 3 principal components, pup sex, female age class, and secondary interaction terms indicated that there was no relationship between any of the dive parameters and pup growth rate $(p>0.05$ for all $3 \mathrm{PC})$; however, the effect of pup sex was significant $\left(F_{1,21}=8.50, \mathrm{p}=0.008\right)$. In addition, the interaction term $\mathrm{PC} 1 \times$ age class was significant $\left(F_{1,21}=6.06, \mathrm{p}=0.023\right)$. To better understand the interaction, young and primeaged females were analyzed separately. In young females, both pup sex and PC1 (dive effort) were significantly related to pup growth rate (sex: $F_{1,9}=7.56, \mathrm{p}=$ 0.022; PC1: $\left.F_{1,9}=7.04, \mathrm{p}=0.026\right)$, while neither were significant in prime-aged females $(p>0.05)$. In young females, there was a negative relationship between PC1 and pup growth rate, indicating that young females with the greatest effort had pups with the slowest growth rates (Fig. 3). Although not significant, there was a positive trend between effort and pup growth rate in male pups of prime-aged females (Fig. 3). There were no significant differences in pup growth rates between the 4 behavioral groups (Table 4, p >0.05), although the group of primiparous females had the lowest mean growth rate.

\section{DISCUSSION}

The foraging and diving behavior recorded at Cape Shirreff demonstrated flexibility in foraging behavior as previously observed for this species (McCafferty et al. 1998b, Lea et al. 2002). Although prey abundance, based on trip duration and pup growth rate, was similar in both years of this study (Goebel et al. 2007, Orben et al. 2007), significant annual differences in 
Table 4. Arctocephalus gazella. Summary statistics of diving parameters for the 4 behavioral dive categories. Group $1=$ high effort; Group 2 = low effort; Group 3 = intermediate effort, high dive rate; Group 4 = intermediate effort. ANOVAs were performed for each parameter excluding Group 2. If the ANOVA was significant, a pair-wise comparison was made (Tukey's test with Bonferroni correction). Groups that were significantly different are labeled with different letter superscripts. ns $=$ not significant

\begin{tabular}{|c|c|c|c|c|c|}
\hline Dive parameters & Group 1 & Group 2 & Group 3 & Group 4 & $\mathrm{p}$ \\
\hline Mass (kg) & $36.4 \pm 3.3^{\mathrm{a}}$ & 48.4 & $47.3 \pm 6.1^{\mathrm{b}}$ & $49.7 \pm 6.9^{b}$ & 0.0042 \\
\hline Age (yr) & $4.25 \pm 0.5^{\mathrm{a}}$ & 12 & $8.0 \pm 3.5^{\mathrm{a}, \mathrm{b}}$ & $11.0 \pm 4.5^{\mathrm{b}}$ & 0.0145 \\
\hline Body condition $\left(\mathrm{kg} \mathrm{cm}^{-1}\right)$ & $0.31 \pm 0.02^{\mathrm{a}}$ & 0.38 & $0.37 \pm 0.03^{b}$ & $0.38 \pm 0.04^{\mathrm{b}}$ & 0.0039 \\
\hline Pup growth rate $\left(\mathrm{g} \mathrm{d}^{-1}\right)$ & $104.7 \pm 49.4$ & 113.5 & $123.8 \pm 28.7$ & $128.8 \pm 25.8$ & ns \\
\hline Day depth (m) & $19.7 \pm 4.4^{\mathrm{a}}$ & 31.2 & $28.3 \pm 1.8^{\mathrm{b}}$ & $21.2 \pm 5.8^{\mathrm{a}}$ & 0.0044 \\
\hline Night depth (m) & $16.2 \pm 2.1^{\mathrm{a}}$ & 17.9 & $10.9 \pm 1.9^{\mathrm{b}}$ & $16.0 \pm 3.1^{\mathrm{a}}$ & 0.0006 \\
\hline Day duration (s) & $84 \pm 13$ & 108 & $98 \pm 7$ & $94 \pm 12$ & ns \\
\hline Night duration (s) & $62 \pm 6^{\mathrm{a}}$ & 72 & $52 \pm 4^{\mathrm{b}}$ & $69 \pm 6^{\mathrm{a}}$ & 0.0001 \\
\hline Night dive rate $\left(\right.$ dives $\left.\mathrm{h}^{-1}\right)$ & $26.0 \pm 3.5^{\mathrm{a}}$ & 13.8 & $26.0 \pm 3.0^{\mathrm{a}}$ & $19.1 \pm 2.1^{\mathrm{b}}$ & 0.0001 \\
\hline Time spent diving night (\%) & $44.8 \pm 4.2^{\mathrm{a}}$ & 27.6 & $36.5 \pm 4.7^{\mathrm{b}}$ & $36.3 \pm 3.9^{\mathrm{b}}$ & 0.005 \\
\hline Dives at night $(\%)$ & $49.7 \pm 6.2^{\mathrm{a}}$ & 28.2 & $41.6 \pm 5.1^{\mathrm{a}}$ & $35.4 \pm 5.2^{\mathrm{b}}$ & 0.0002 \\
\hline Vertical depth per hour of night $\left(\mathrm{m} \mathrm{h}^{-1}\right)$ & $836 \pm 61^{\mathrm{a}}$ & 494 & $557 \pm 110^{\mathrm{b}}$ & $607 \pm 114^{\mathrm{b}}$ & 0.0009 \\
\hline Vertical depth at night (\%) & $45.2 \pm 3.0^{\mathrm{a}}$ & 18.3 & $21.8 \pm 2.1^{\mathrm{b}}$ & $29.6 \pm 6.1^{\mathrm{c}}$ & 0.0001 \\
\hline Mean trip duration $(\mathrm{d})$ & $4.26 \pm 0.96^{\mathrm{a}}$ & 1.58 & $2.80 \pm 1.00^{b}$ & $2.93 \pm 0.55^{b}$ & 0.0113 \\
\hline Proportion of time at sea (\%) & $70.2 \pm 4.1^{\mathrm{a}}$ & 45 & $61.5 \pm 7.7^{\mathrm{a}, \mathrm{b}}$ & $60.2 \pm 5.1^{\mathrm{b}}$ & 0.0217 \\
\hline Proportion of dives in bouts (\%) & $94.3 \pm 1.4$ & 86.8 & $92.1 \pm 2.6$ & $93.4 \pm 1.2$ & ns \\
\hline Number of dives per bout (n) & $14.1 \pm 1.2^{\mathrm{a}}$ & 10 & $12.6 \pm 1.0^{\mathrm{b}}$ & $11.5 \pm 0.7^{\mathrm{c}}$ & 0.0001 \\
\hline$N(2005)$ & 1 & 0 & 0 & 12 & - \\
\hline N (2006) & 3 & 1 & 8 & 2 & - \\
\hline N (Total) & 4 & 1 & 8 & 14 & - \\
\hline
\end{tabular}

diving behavior were evident. Additionally, maternal traits and individual quality influenced the foraging behavior of seals. Foraging primarily occurred during the evening and night. Overall dive depths were shallow, similar to the dive depths of other populations that feed primarily on Antarctic krill Euphausia superba (Boyd \& Croxall 1992, Goebel et al. 2007).

\section{Influence of maternal traits and individual on foraging behavior}

Female age, mass, year, trip number, and individual accounted for a significant amount of variation in the foraging behavior of lactating Antarctic fur seals, but these factors affect diving behavior in different ways. While female body condition did not explain any of the variation in the diving behavior, mass was important in explaining variation in dive effort, and age was a significant predictor of variation in daytime dive characteristics (Table 3). Larger females had slightly lower dive effort. Because larger females have greater energy reserves that can act as a buffer (Beauplet \& Guinet 2007), larger females may not work as hard as smaller animals lacking this buffer (Bowen et al. 2001). Young females did not dive as deep or as long during the day or night. If young females have a reduced aerobic capacity because of their smaller size (Costa 1993), such a difference in behavior would be expected. However, at this location the fur seals may not be pushing their aerobic capacity since they forage at shallow depths; thus, mass would not be expected to be as important.

The MDS and cluster analysis provided further support that age influences foraging behavior. The first group to separate out of the cluster analysis consisted of 4 primiparous females (Fig. 1). This group had significantly longer trip durations, spent more of the night hours diving, travelled the greatest vertical distance per hour of night, and spent the greatest proportion of time at sea, suggesting increased foraging effort relative to other females as predicted (Table 4). Although this group contained some of the smallest individuals, size alone cannot explain all of the differences because other small primiparous females clustered with the prime-aged females.

Experience is likely important in explaining why the group of primiparous females behave differently than the other females. While most primiparous females return to the colony in the year or two before pupping for the first time, they often do not arrive until later in the year (M. E. Goebel unpubl. data); therefore, they may not be familiar with early season foraging conditions. During prospecting, they make longer and more irregular foraging trips (M. E. Goebel unpubl. data); therefore, first-time breeders may not know where to find reliable food sources close to the colony and may not be accustomed to the constraints of returning regularly to a pup. This could explain the longer foraging trip durations and greater time spent at sea. 

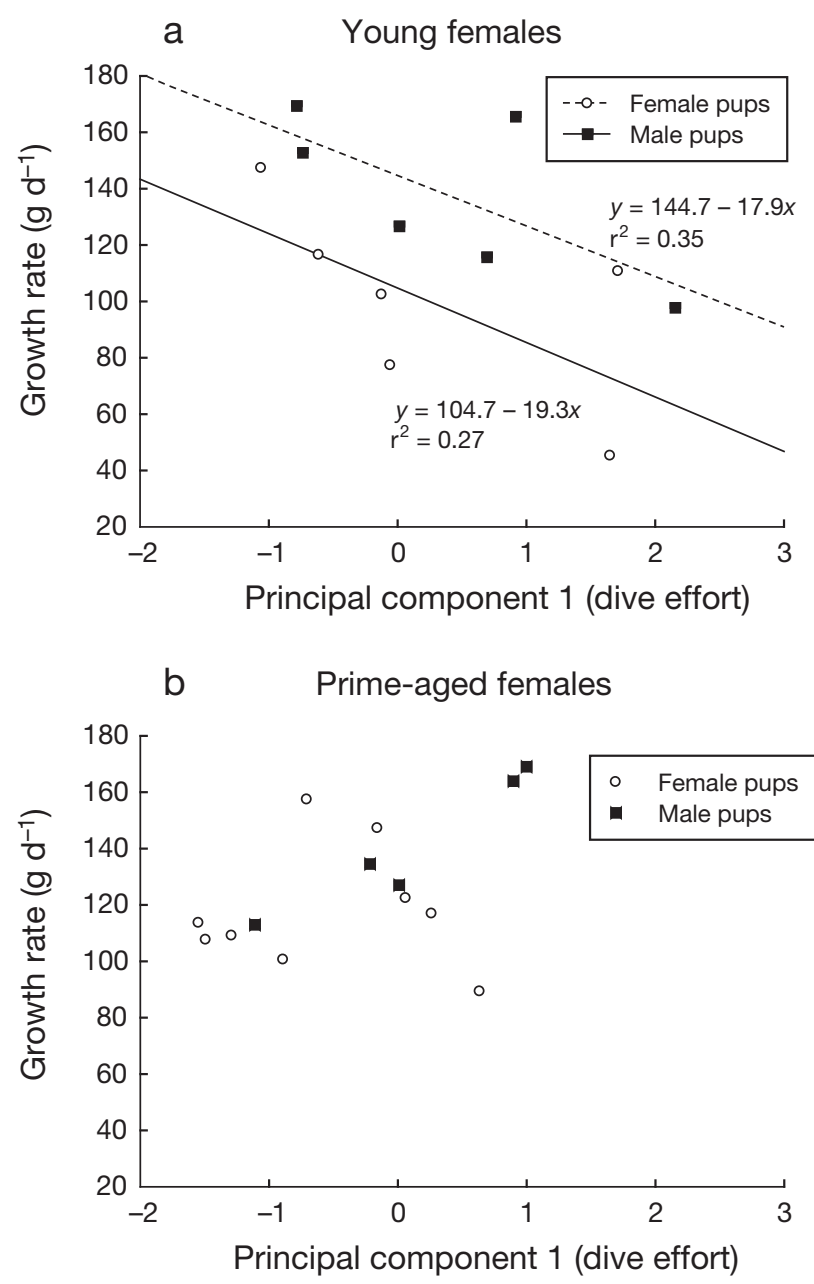

Fig. 3. Arctocephalus gazella. Relationship between principal component 1 (dive effort) and pup growth rate for (a) young and (b) prime-aged females. When all females are combined, there is no relationship between effort and growth rate; however, there is a significant relationship between effort and pup growth rate in young females (sex: $F_{1,9}=7.56, \mathrm{p}=0.022$; PC1: $F_{1,9}=7.04, \mathrm{p}=0.026$ ). This relationship is not present in prime-aged females $(p>0.05)$.

The greater variability in foraging effort and diving behavior seen in young females compared to the prime-aged females could also be explained by a higher proportion of lower-quality individuals in the young age classes that have yet to be selected out of the breeding population (Annett \& Pierotti 1999, Mauck et al. 2004, Beauplet et al. 2006). Beauplet et al. (2006) found that in sub-Antarctic fur seals there was a higher proportion of low-quality individuals in the lower age classes. This has also been documented in avian species (Annett \& Pierotti 1999, Mauck et al. 2004). For example, Mauck et al. (2004) found that the Leach's storm petrels which were most successful in the first 2 breeding attempts tended to live longer and have higher lifetime reproductive success.
In addition to maternal traits influencing dive behavior, there were significant differences in diving behavior between the 2 years of the study and as the season progressed (Tables 1, 2, \& 3). All the females from the 2005 season, except one primiparous female, clustered into one group (Fig. 1, Group 4). In contrast, the females from 2006 were found in all of the 4 behavioral groups, but most were in Group 3 (Fig. 1, Table 4). The mixed-effect models supported the differences indicated by the cluster analysis. Year was important in the models with the response variables PC2 and PC3, representing night- and daytime dive characteristics, respectively. In the 2006 season, females were diving to significantly deeper depths and longer during the day. There was no difference in the dive depth at night between the 2 groups; however, the 2005 females were diving for longer at night (Table 2).

One explanation for the differences between Group 3 and Group 4 is that in 2005, the fur seals were feeding in slope or oceanic habitats, and in 2006 they were feeding primarily on the shelf (Goebel et al. 2000, Ichii et al. 2007). In most years, the shelf region is dominated by less mature adult krill, while over the slope and oceanic regions gravid krill and myctophids are dominant (Siegel 1988, Ichii et al. 2007, Loeb et al. 2007). Oceanographic conditions were different in the 2 years of the study (Needham \& van der Berg 2006, 2007). In 2005 a front was present in the oceanic region (Needham \& van der Berg 2006, Ichii et al. 2007), but in 2006 this front was absent (Needham \& van der Berg 2007). Fronts aggregate prey (Polovina et al. 2000), so in the absence of the oceanic front in 2006 foraging may have changed to the shelf region where prey was still available (Ichii et al. 2007). This idea is supported by the previous finding that seals dive deeper when diving on the shelf (Goebel et al. 2000). These data suggest that, although time spent foraging may not change, females are able to compensate for change in prey availability or distribution by altering diving behavior (Costa 2007).

\section{Maternal investment}

Variation in foraging behavior could be attributed to female identity, age, mass, and changes in the environment, but foraging behavior did not significantly affect the wide variation in pup growth rates (from 45 to $169 \mathrm{~g} \mathrm{~d}^{-1}$ ). Apparently females were able to modify their foraging or provisioning efficiency in ways that mitigated environmental variation so that the growth rates of the pups were not affected by changes in prey characteristics. In a long-term, population-level study, Reid (2002) did not find any relationship between pup growth rate and trip duration. Additionally, Boyd et al. 
(1991) and Lunn et al. (1993) found a relationship between trip duration and pup growth only in a year of low food availability and suggested that in years of favorable feeding conditions, differences in pup growth rates were likely due to differences in female feeding efficiency. This idea is supported by the current study, which found no effect of foraging behavior on pup growth during $2 \mathrm{yr}$ of favorable feeding conditions.

When young and prime-aged females were analyzed separately, there was a negative relationship between dive effort and pup growth rate in the young females (Fig. 3a). This suggests that young females with the greatest effort also have pups with the lowest growth rates. This relationship was not seen in the prime-aged females (Fig. 3b). Previous studies have found that in years of reduced prey availability, females with shorter trip durations had pups with the greatest pup growth rate (Lunn et al. 1993). Longer trips often result in a larger transfer of energy per trip, but over time, pups of females with shorter trips grow faster (Guinet et al. 2000). In this study, only young females had trips greater than $3.5 \mathrm{~d}$. This supports the hypothesis that young females lack experience and may not be as successful at finding prey patches close to the rookery. Furthermore, young females had smaller masses than prime-aged females. Since prime-aged females have greater energy reserves, they may be able to provision pups even after less successful foraging trips. Small females may lack this flexibility and need to exhibit greater effort to successfully provision their offspring.

We used pup growth rate as an index of maternal investment. However, pup growth rate may be affected by factors other than maternal investment, such as weather and individual differences in pup physiology and/or behavior (Guinet et al. 1999, Donohue et al. 2002, Arnould et al. 2003). Milk intake measurements could provide a better index of maternal investment (Arnould et al. 1996a).

\section{Linking maternal traits, foraging behavior, and maternal investment}

Maternal traits, environment, and female identity were all found to influence the foraging behavior of lactating Antarctic fur seals. Female mass and age were both found to influence diving behavior but in different ways, suggesting that the age differences may include experience as well as physiology. Although age and size seem to influence foraging behavior, no relationships between foraging behavior and pup growth rate were seen, except in the youngest females. Females also altered behavior in response to annual variation in the environment in a way that yielded consistent overall growth rates between years. These data suggest that females are optimizing their foraging behavior in order to maximize the rate of food delivery to their young.

Individual variability was apparent in all diving parameters investigated, indicating that other intrinsic factors besides mass and age are important. The females in this study were assigned into 4 behavior groups, as at Îles Kerguelen (Lea et al. 2002). However, unlike in that study, much of the variation between the groups could be explained by year instrumented or female age, and was not consistent between years. The lack of a diversity of distinct strategies that persist over time in the population may indicate ample resource availability at Cape Shirreff, as the leading hypothesis selecting for dietary specialization and niche separation within a population is limited resources (Roughgarden 1972, Thompson \& Colgan 1990). At Îles Kerguelen, the fur seal population consists of smaller females (from $\sim 30$ to $35 \mathrm{~kg}$ ) that feed primarily on myctophids, dive deeper, and have longer trips even in years of favorable feeding conditions, suggesting that they have to work harder than the Cape Shirreff fur seals (Lea et al. 2002, Lea et al. 2006). This could explain why the Kerguelen population exhibits distinct diving strategies. In contrast, in the current study it appears that there were favorable feeding conditions during both years, although prey likely occupied different habitats as evidenced by dive behavior. Potentially in years of lower food abundance, more distinct strategies would be seen.

In years of poor foraging conditions, experience and size will likely have a greater effect on foraging behavior, leading to a decreased growth rate in the pups. A study on Antarctic fur seals in the Kerguelen Archipelago found that maternal size influenced pup growth rate only in a year of poor prey availability (Lea et al. 2006). A similar relationship was found in sub-Antarctic fur seals at Amsterdam Island (Georges \& Guinet 2000). It has been proposed that when prey was farther from the breeding colonies, larger females were at an advantage because they could store more energy reserves, thereby increasing the time they spend in a high-quality prey patch (Georges \& Guinet 2000). Larger females would also be at an advantage to exploit deeper food resources owing to their increased aerobic capacity (Lea et al. 2006). In this study, we found that experience influenced foraging behavior, with primiparous females tending to have longer foraging trips and spending more time diving even in good years. In a poor foraging year, in which females have to travel further or dive deeper, small, inexperienced females may be pushed to their limits, resulting in lower growth rates in their pups and possibly pup death. 
Few strong relationships between foraging behavior and pup growth were found, suggesting that individual differences in female foraging efficiency, and potentially differences in pup physiology and behavior, are responsible for the large variability in pup growth rates. While the Antarctic fur seals at Cape Shirreff did not demonstrate distinct foraging strategies, the variability observed in their diving behavior may persist because it allows flexibility in response to an unpredictable environment, thus facilitating reproductive success in years of marginal or low prey availability (Arnould et al. 1996b, McCafferty et al. 1998b, Annett \& Pierotti 1999).

Acknowledgements. We thank all those who assisted with the collection and analysis of the data, in particular C. Champagne, R. Haner, P. Robinson, and S. Seganti. Logistical support was provided by the US AMLR program, the National Science Foundation US Antarctic Program and Raytheon Polar Services. This research was funded by the US AMLR program and NSF OPP grant \#0440687 to D.P.C, D.E.C., \& M.E.G. B.I.M. was supported by the United States Environmental Protection Agency (EPA) under the Science to Achieve Results (STAR) Graduate Fellowship Program and a NSF graduate fellowship. EPA has not officially endorsed this publication, and the views expressed herein may not reflect the views of the EPA. Animal use was completed under National Marine Fisheries Service permit \#774-1649. All procedures were approved by the University of California, Santa Cruz, Animal Use Committee.

\section{LITERATURE CITED}

Annett CA, Pierotti R (1999) Long-term reproductive output in western gulls: consequences of alternate tactics in diet choice. Ecology 80:288-297

Arnould JPY, Boyd IL, Socha DG (1996a) Milk consumption and growth efficiency in Antarctic fur seal (Arctocephalus gazella) pups. Can J Zool 74:254-266

Arnould JPY, Boyd IL, Speakman JR (1996b) The relationship between foraging behavior and energy expenditure in Antarctic fur seals. J Zool (Lond) 239:769-782

Arnould JPY, Luque SP, Guinet C, Costa DP, Kingston J, Shaffer SA (2003) The comparative energetics and growth strategies of sympatric Antarctic and subantarctic fur seal pups at îles Crozet. J Exp Biol 206:4497-4506

Baker JD, Donohue MJ (2000) Ontogeny of swimming and diving in northern fur seal (Callorhinus ursinus) pups. Can J Zool 78:100-109

Beauplet G, Guinet C (2007) Phenotypic determinants of individual fitness in female fur seals: larger is better. Proc $\mathrm{R}$ Soc Lond B 274:1877-1883

Beauplet G, Dubroca L, Guinet C, Cherel Y, Dabin W, Gagne C, Hindell MA (2004) Foraging ecology of subantarctic fur seals Arctocephalus tropicalis breeding on Amsterdam Island: seasonal changes in relation to maternal characteristics and pup growth. Mar Ecol Prog Ser 273:211-225

- Beauplet G, Barbraud C, Dabin W, Kussener C, Guinet C (2006) Age-specific survival and reproductive performances in female subantarctic fur seals: evidence of senescence and individual quality. Oikos 112:430-441

Belbin L, Faith DP, Milligan GW (1992) A comparison of two approaches to beta-flexible clustering. Multivar Behav
Res 27:417-433

Bolger DT, Patten MA, Bostock DC (2005) Avian reproductive failure in response to an extreme climatic event. Oecologia 142:398-406

Bowen WD, Iverson SJ, Boness DJ, Oftedal OT (2001) Foraging effort, food intake and lactation performance depend on maternal mass in a small phocid seal. Funct Ecol 15: 325-334

Boyd IL, Croxall JP (1992) Diving behavior of lactating Antarctic fur seals. Can J Zool 70:919-928

> Boyd IL, Lunn NJ, Barton T (1991) Time budgets and foraging characteristics of lactating Antarctic fur seals. J Anim Ecol 60:577-592

> Boyd IL, Arnould JPY, Barton T, Croxall JP (1994) Foraging behavior of Antarctic fur seals during periods of contrasting prey abundance. J Anim Ecol 63:703-713

Costa DP (1993) The relationship between reproductive and foraging energetics and the evolution of the Pinnipedia. Symp Zool Soc Lond 66:293-314

> Costa DP (2007) A conceptual model of the variation in parental attendance in response to environmental fluctuation: foraging energetics of lactating sea lions and fur seals. Aquat Conserv 17:S44-S52

Crocker DE, Costa DP, Le Boeuf BJ, Webb PM, Houser DS (2006) Impact of El Niño on the foraging behavior of female northern elephant seals. Mar Ecol Prog Ser 309: $1-10$

Daunt F, Wanless S, Harris MP, Money L, Monaghan P (2007) Older and wiser: improvements in breeding success are linked to better foraging performances in European shags. Funct Ecol 21:561-567

Doidge DW, McCann TS, Croxall JP (1986) Attendance behavior of Antarctic fur seals. In: Gentry RL, Kooyman GL (eds) Fur seals: maternal strategies on land and at sea. Princeton University Press, Princeton, NJ, p 102-114

> Donohue MJ, Costa DP, Goebel E, Antonelis GA, Baker JD (2002) Milk intake and energy expenditure of free-ranging northern fur seal, Callorhinus ursinus, pups. Physiol Biochem Zool 75:3-18

> Draulans D (1982) Foraging and size selection of mussels by the tufted duck Aythya fuligula. J Anim Ecol 51:943-956

Galbraith H, Hatch JJ, Nisbet ICT, Kunz TH (1999) Agerelated changes in efficiency among breeding common terns Sterna hirundo: measurement of energy expenditure using doubly-labelled water. J Avian Biol 30:85-96

Gales NJ, Mattlin RH (1998) Fast, safe, field-portable gas anesthesia for otariids. Mar Mamm Sci 14:355-361

Gentry RL (1997) Behavior and ecology of the northern fur seal. Princeton University Press, Princeton, NJ

Georges JY, Guinet C (2000) Maternal care in the subantarctic fur seals on Amsterdam Island. Ecology 81:295-308

Goebel ME (1988) Duration of feeding trips and age-related reproductive success of lactating females, St. Paul Island, Alaska. In: Kozloff P, Kajimura H (eds) Fur seal investigations, 1985. NOAA Tech Memo NMFS F/NWC-146, p 28-33

Goebel ME, Costa DP, Crocker DE, Sterling JT, Demer DA (2000) Foraging ranges and dive patterns in relation to bathymetry and time-of-day of Antarctic fur seals, Cape Shirreff, Livingston Island, Antarctica. In: Davidson W, Howard-Williams C, Broady P (eds) Antarctic ecosystems: models for wider ecological understanding. New Zealand Natural Sciences, Christchurch, p 47-50

Goebel ME, Rutishauser M, Parker BW, Banks AR, Costa DP, Gales NJ, Holt RS (2001) Pinniped research at Cape Shirreff, Livingston Island 1999/2000. NOAA-TM-NMFSSWFSC-302 
Goebel ME, McDonald BI, Haner R, Champagne C, Lipsky JD, Holt RS (2007) Pinniped research at Cape Shirreff. NOAA-TM-NMFS-SWFSC-409

Gower JC (1971) An illustration of a new technique for comparing different distance analyses. Am J Phys Anthropol 35:280-281

Guinet C, Goldsworthy SD, Robinson S (1999) Sex differences in mass loss rate and growth efficiency in Antarctic fur seal (Arctocephalus gazella) pups at Macquarie Island. Behav Ecol Sociobiol 46:157-163

Guinet C, Lea MA, Goldsworthy SD (2000) Mass change in Antarctic fur seal (Arctocephalus gazella) pups in relation to maternal characteristics at the Kerguelen Islands. Can J Zool 78:476-483

Hill DA, Ellis N (1984) Survival and age related changes in the foraging behavior and time budget of tufted ducklings Aythya fuligula. Ibis 126:544-550

Ichii T, Bengtson JL, Boveng PL, Takao Y and others (2007) Provisioning strategies of Antarctic fur seals and chinstrap penguins produce different responses to distribution of common prey and habitat. Mar Ecol Prog Ser 344:277-297

> Jodice PGR, Roby DD, Turco KR, Suryan RM and others (2006) Assessing the nutritional stress hypothesis: relative influence of diet quantity and quality on seabird productivity. Mar Ecol Prog Ser 325:267-279

Jonsson P, Hartikainen T, Koskela E, Mappes T (2002) Determinants of reproductive success in voles: space use in relation to food and litter size manipulation. Evol Ecol 16:455-467

Kato A, Watanuki Y, Naito Y (2003) Annual and seasonal changes in foraging site and diving behavior in Adelie penguins. Polar Biol 26:389-395

Lea MA, Hindell M, Guinet C, Goldsworthy S (2002) Variability in the diving activity of Antarctic fur seals, Arctocephalus gazella, at Iles Kerguelen. Polar Biol 25:269-279

Lea MA, Guinet C, Cherel Y, Duhamel G, Dubroca L, Pruvost P, Hindell M (2006) Impacts of climatic anomalies on provisioning strategies of a Southern Ocean predator. Mar Ecol Prog Ser 310:77-94

Lea MA, Guinet C, Cherel Y, Hindell M, Dubroca L, Thalmann S (2008) Colony-based foraging segregation by Antarctic fur seals at the Kerguelen Archipelago. Mar Ecol Prog Ser 358:273-287

Loeb V, Dietrich K, Driscoll R, Green K and others (2007) Net sampling. NOAA-TM-NMFS-SWFSC-409

Lunn NJ, Boyd IL, Barton T, Croxall JP (1993) Factors affecting the growth rate and mass at weaning of Antarctic fur seals at Bird Island, South Georgia. J Mammal 74:908-919

MacArthur RH, Pianka ER (1966) On the optimal use of a patchy environment. Am Nat 100:603-609

Mauck RA, Huntington CE, Grubb TC Jr (2004) Age-specific reproductive success: evidence for the selection hypothesis. Evolution 58:880-885

McCafferty DJ, Boyd IL, Taylor FE (1998a) Diving behavior of Antarctic fur seal (Arctocephalus gazella) pups. Can J Zool 76:513-520

> McCafferty DJ, Boyd IL, Walker TR, Taylor RI (1998b) Foraging responses of Antarctic fur seals to changes in the marine environment. Mar Ecol Prog Ser 166:285-299

McKnight SK (1998) Effects of food abundance and environmental parameters on foraging behavior of gadwalls and

Editorial responsibility: Michael Castellini,

Fairbanks, Alaska, USA
American coots in winter. Can J Zool 76:1993-1998

Miller AK, Trivelpiece WZ (2008) Chinstrap penguins alter foraging and diving behavior in response to the size of their principle prey, Antarctic krill. Mar Biol 154:201-208

Needham D, van der Berg M (2006) Physical oceanography. NOAA-TM-NMFS-SWFSC-397

Needham D, van der Berg M (2007) Physical oceanography. NOAA-TM-NMFS-SWFSC-409

Orben RA, Chisholm SE, Miller AK, Trivelpiece WZ (2007) Seabird research at Cape Shirreff, Livingston Island, Antarctica, 2006/07. NOAA-TM-NMFS-SWFSC-409

Orians GH (1981) Foraging behavior and the evolution of discriminatory abilities. In: Kamil AC, Sargent TD (eds) Foraging behavior: ecological, ethological, and physiological aspects. Garland Press, New York, NY, p 389-405

Orians GH, Pearson NE (1979) On the theory of central place foraging. In: Horn DJ, Stairs ET, Mitchell RT (eds) Analysis of ecological systems. Ohio State University Press, Columbus, OH, p 155-177

> Percival SM, Evans PR (1997) Brent geese Branta bernicla and Zostera; factors affecting the exploitation of a seasonally declining food resource. Ibis 139:121-128

Petit LJ, Petit DR, Petit KE, Fleming WJ (1990) Annual variation in foraging ecology of prothonotary warblers during breeding season. Auk 107:146-152

Polovina JJ, Kobayashi DR, Parker DM, Seki MP, Balazs GH (2000) Turtles on the edge: movement of loggerhead turtles (Caretta caretta) along oceanic fronts, spanning longline fishing grounds in the central North Pacific, 1997-1998. Fish Oceanogr 9:71-82

Reid K (2002) Growth rates of Antarctic fur seals as indices of environmental conditions. Mar Mamm Sci 18:469-482

Robinson SA, Goldsworthy SG, van den Hoff J, Hindell MA (2002) The foraging ecology of two sympatric fur seal species, Arctocephalus gazella and Arctocephalus tropicalis, at Macquarie Island during the austral summer. Mar Freshw Res 53:1071-1082

Roughgarden J (1972) Evolution of niche width. Am Nat 106: $683-718$

Schreer JF, Kovacs KM (1997) Allometry of diving capacity in air-breathing vertebrates. Can J Zool 75:339-358

Siegel V (1988) A concept of seasonal variation of krill (Euphausia superba) distribution and abundance west of the Antarctic Peninsula. In: Sahrhage D (ed) Antarctic Ocean and resources variability. Springer-Verlag, Berlin, p 219-230

Skorka P, Wojcik JD (2008) Habitat utilization, feeding tactics and age related feeding efficiency in the Caspian Gull Larus cachinnans. J Ornithol 149:31-39

Stearns SC (1992) The evolution of life histories. Oxford University Press, Oxford

Stephens DW, Krebs JR (1986) Foraging theory. Princeton University Press, Princeton, NJ

Thompson ID, Colgan PW (1990) Prey choice by marten during a decline in prey abundance. Oecologia 83:443-451

- Tremblay Y, Cherel Y (2003) Geographic variation in the foraging behaviour, diet and chick growth of rockhopper penguins. Mar Ecol Prog Ser 251:279-297

$>$ Trites AW (1991) Fetal growth of northern fur seals: lifehistory strategy and sources of variation. Can J Zool 69: 2608-2617

Submitted: April 1, 2009; Accepted: September 3, 2009

Proofs received from author(s): November 5, 2009 